\title{
The Association of Cholelithiasis and Colorectal Cancer
}

\author{
Sărăcuț C, Molnar C, Pantiru A, Russu C, Roșca C, Voidăzan S, Copotoiu C \\ Surgery Clinic I, County Emergency Clinical Hospital, Tîrgu Mureș, Romania
}

\begin{abstract}
Background: In the literature there are a number of studies that suggest a possible correlation between cholelithiasis/cholecystectomy and colorectal cancer. The exposure of the colon mucosa to the action of bile acids that potentially have a carcinogenic effect due to the change in anatomy after cholecystectomy, seems to be the explanation of this association. The purpose of this paper was to search for such a correlation in our study group.

Methods: We performed a retrospective cross-sectional study, analyzing the patients admitted to the First Surgical Clinic of the County Emergency Clinical Hospital Tîrgu Mureș, between January 1st, 2005 - December 31st, 2010. Analyzing the medical records, operation protocols and histopathological results, we paid attention to demographics, location of neoplasia, the time elapsed since the cholecystectomy to the discovery of neoplasia, histological types, trying to perform correlations between these parameters and the lithiasic factor.

Results: Out of the 534 patients admitted and operated with the diagnosis of colorectal cancer, $15.6 \%(n=83)$ showed a history of gallbladder stone affection. Most patients came from urban areas, the average age was 67.2 (range 39-88 years), females were more affected. The most common locations were: the sigmoid colon (26.5\%), rectum (36.3\%) and the most common histological form was moderately differentiated adenocarcinoma.

Conclusions: Similar to other studies, our work suggests a slight increase in the incidence of colorectal cancer in patients that underwent a cholecystectomy, without drawing a firm conclusion. We deem it necessary to see if diet changes of the Romanian population affect this relationship.
\end{abstract}

Keywords: cholelithiasis, cholecystectomy, colorectal cancer

Received: 11 June 2013 / Accepted: 12 February 2014

\section{Introduction}

There are many studies in the literature that suggest a possible correlation between gallstones/cholecystectomy and colorectal cancer. The involvement of bile acids in the pathogenesis of both diseases could be the substrate in this association. Primary bile acids (cholic acid and chenodeoxicolic acid) are produced by the liver from cholesterol. These acids are temporarily storred in the gallbladder. From there they are released regularly in the duodenum with a role in emulsifying fats. Secondary bile acids are formed in the small intestine by deconjugation of primary bile acids (deoxycholic acid from cholic acid and lithocholic acid from chenodezoxicolic). Western-style diet (high fat content) increases the level of bile acids in the gastrointestinal tract, thus explaining the possible association between biliary disease and colon cancer [1]. Secondary bile acids (deoxycholic acid) exert a carcinogenic effect through several mechanisms: changes of cell membrane surfactant [2,3], calcium ions fixation [4], activation of protein kinase $\mathrm{C}[5,6]$, changes in DNA $[7,8]$.

Another explanation may be that after cholecystectomy or in the presence of gall stones (equivalent to a "functional cholecystectomy"), the bile is continuously eliminated in the duodenum causing a prolonged exposure of the mu-

Correspondence to: Claudiu Saracut

E-mail: clau.saracut@yahoo.com cosa to a larger amount of secondary bile acids with cocarcinogenic effect [9].

The aim of this study is to identify a possible correlation between cholelithiasis/cholecystectomy and colorectal cancer.

\section{Methods}

We conducted a retrospective, cross-sectional study following patients admitted between January 1st, 2005 - December $31^{\text {st }}, 2010$ in the Surgical Clinic I of the County Emergency Clinical Hospital Tîrgu Mureș. Analyzing clinical observation sheets, surgical protocols, histopathological results, we included in our database patients diagnosed with colorectal cancer taking into account demographic aspects, anatomical location of the tumor, histopathological forms, and immediate postoperative evolution.

We paid attention to the biliary pathology associated with colorectal cancer (cholecystectomy for gallstones, gallstones confirmed by ultrasound on admission) and patients with colorectal cancer without cholelithiasis. Based on our observations, the 534 patients with colorectal cancer were divided into three groups: the first group included patients with a history of cholecystectomy ( 49 cases), the second group included 34 patients with confirmed diagnosis of gallstones on admission and the third group included patients with colorectal cancer without cholelithiasis (451 cases). 
Inclusion criteria:

- patients with colorectal cancer and with cholelithiasis or a history of biliary pathology (who underwent cholecystectomy/with cholelithiasis) hospitalized and operated in our clinic between January $1^{\text {st }}, 2005$ and December 31 ${ }^{\text {st }}, 2010$;

- patients with histologically confirmed colorectal cancer;

- adult patients over 18 years.

Exclusion criteria:

- patients admitted/treated in other services

- patients without malignancy (confirmed after surgery);

- patients with anal cancer.

Statistical analysis was performed using MedCalc Software (Version 12.3.0 bvba, Mariakerke, Belgium). ANOVA test was used to assess the differences in continuous variables backgrounds (age, expressed as mean \pm SD) and Kruskal Wallis test for non-parametric variables (days of hospitalization, expressed as median and range), while the $\chi^{2}$ test was used for category variables (expressed as no (\%). We interpreted all the tests we have performed to the threshold of significance $\mathrm{p}=0.05$ and statistical significance was considered for $\mathrm{p}$-values less than the threshold value of significance.

\section{Results}

The main group of 534 patients with colorectal cancer is characterized by a masculine predominance (321 individuals, 60\%). Gender distribution in the three study groups show a female predominance in the group of patients that underwent cholecystectomy and the patients with confirmed cholelithiasis on admission; this is characterized by a general ratio female/male of $2: 1$. In the third group of patients, patients without gallstones the ratio is inverted: female/male ratio of $1: 2$.

We found a mean age of 67.2 years in patients with cholelithiasis, significantly higher than the average age of patients without gallstones $(\mathrm{p}=0.04)$. The most affected age segment was 60-69 years (33.3\%), followed by 70-79 years $(26.2 \%)$ and $50-59$ years $(25.4 \%)$. We found a numerically lower casuistry in patients under the age of 40 and over the age of 80 .

Cholecystectomy and cholelithiasis was found in patients primarily from an urban environment.

Depending on the location of the tumor, we found that almost one third of the cases occurred in the rectum (194 cases: $36.3 \%$ ), followed by the sigmoid (136 cases: $25.4 \%$ ) and those located in the ascending colon (91 cases: 17\%). The group of patients that underwent cholecystectomy was characterized by the location of the tumor mainly in the sigmoid colon $(26.5 \%)$, followed by the rectum $(22.4 \%)$ and the ascending colon (16.3\%). We encountered a similar situation in the group of patients with confirmed cholelithiasis on admission. In the third group of patients the most frequent location by far was the rectum (39.1\%).

Characteristics of patients included in our study are shown in Table I.

Attention was paid to the synchronous tumors, with tumors identified at several levels of the colon and rectum. Synchronous tumors were found in $2.04 \%$ of patients that had a history of cholecistectomy, in $2.9 \%$ of patients with cholelithiasis and in $4 \%$ of patients without gallstones. We found no statistically significant difference $(p>0.05)$ between these percentages.

Rectal cancer occured predominantly in individuals without gallstones, a percentage significantly higher than in patients that underwent a cholecystectomy, as shown in

Table I. Demographic and clinical characteristics of the study subjects

\begin{tabular}{|c|c|c|c|c|c|}
\hline Parameters & Categories & $\begin{array}{c}\text { Patients that underwent } \\
\text { cholecystectomy } \\
49(9.2 \%)\end{array}$ & $\begin{array}{c}\text { Patients with confirmed chole- } \\
\text { lithiasis on admission } \\
34(6.4 \%)\end{array}$ & $\begin{array}{l}\text { Patients without } \\
\text { cholelithiasis } \\
451(84.5 \%)\end{array}$ & $P$ value \\
\hline Gender n (\%) & female/male & $33(67.3) / 16(32.7)$ & $21(61.7) / 13$ (38.3) & 159 (35.2)/292 (64.7) & $0.0001^{*}$ \\
\hline Age mean $\pm S D$ & (years) & $64.9 \pm 10.1$ & $67.2 \pm 10.5$ & $63.1 \pm 11.3$ & $0.04^{\star \star}$ \\
\hline \multirow[t]{6}{*}{ Age groups n (\%) } & $<40$ & $1(2.04)$ & $0(0)$ & $14(3.1)$ & \\
\hline & $40-49$ & $0(0)$ & $2(5.9)$ & $35(7.7)$ & \\
\hline & $50-59$ & $14(28.6)$ & 7 (20.6) & $115(25.5)$ & $0.54^{\star}$ \\
\hline & $60-69$ & $18(36.7)$ & $10(29.4)$ & 150 (33.2) & \\
\hline & $70-79$ & $12(24.5)$ & $13(38.2)$ & $115(25.5)$ & \\
\hline & $>80$ & $4(8.2)$ & $2(5.9)$ & $22(4.8)$ & \\
\hline \multirow[t]{2}{*}{ Environment } & Rural & $15(30.6)$ & $10(29.4)$ & $183(40.6)$ & $0.19^{\star}$ \\
\hline & Urban & $34(69.4)$ & $24(70.6)$ & $268(59.4)$ & \\
\hline \multirow[t]{7}{*}{ Tumor location } & Ascending & $8(16.3)$ & $4(11.7)$ & 79 (17.5) & \\
\hline & Transverse & $4(8.1)$ & $3(8.8)$ & $25(5.5)$ & \\
\hline & Descending & $4(8.2)$ & $2(5.9)$ & $41(9.1)$ & $0.56^{*}$ \\
\hline & Sigmoid & $13(26.5)$ & $9(26.5)$ & $114(25.3)$ & \\
\hline & Recto-sigmoidian & $8(16.3)$ & $8(23.5)$ & $81(17.9)$ & \\
\hline & Rectal & $11(22.4)$ & 7 (20.6) & $176(39.1)$ & \\
\hline & Syncronous & $1(2.04)$ & $1(2.9)$ & $18(4.0)$ & \\
\hline $\begin{array}{l}\text { Hospitalisation days } \\
\text { Median (range) }\end{array}$ & Days Median (range) & $12(3-40)$ & $13(7-60)$ & $13(1-110)$ & $0.24^{\star \star \star}$ \\
\hline
\end{tabular}


Table II. Cancer location in patients that underwent a cholecystectomy vs. patients without cholelithiasis

\begin{tabular}{|c|c|c|c|c|}
\hline Parameter & Categories & $\begin{array}{c}\text { Patients that underwent } \\
\text { cholecystectomy } \\
49(9.2 \%)\end{array}$ & $\begin{array}{l}\text { Patients without } \\
\text { cholelithiasis } \\
451(84.5 \%)\end{array}$ & $P$ value \\
\hline \multirow[t]{7}{*}{ Location } & Ascending & $8(16.3)$ & 79 (17.5) & 0.91 \\
\hline & Transverse & $4(8.1)$ & $25(5.5)$ & 0.6 \\
\hline & Descending & $4(8.2)$ & $41(9.1)$ & 0.95 \\
\hline & Sigmoid & $13(26.5)$ & $114(25.3)$ & 0.97 \\
\hline & Recto-sigmoidian & $8(16.3)$ & $81(17.9)$ & 0.93 \\
\hline & Rectal & $11(22.4)$ & $176(39.1)$ & 0.03 \\
\hline & Syncronous & $1(2.04)$ & $18(4.0)$ & 0.7 \\
\hline
\end{tabular}

Table III. Cancer location in patients with cholelithiasis vs. patients without cholelithiasis

\begin{tabular}{|c|c|c|c|c|}
\hline Parameter & Categories & $\begin{array}{c}\text { Patients with confirmed cholelithiasis } \\
\text { on admission } \\
34(6.4 \%)\end{array}$ & $\begin{array}{l}\text { Patients without } \\
\text { cholelithiasis } \\
451(84.5 \%)\end{array}$ & $P$ value \\
\hline \multirow[t]{7}{*}{ Location } & Ascending & $4(11.7)$ & $79(17.5)$ & 0.52 \\
\hline & Transverse & $3(8.8)$ & $25(5.5)$ & 0.6 \\
\hline & Descending & $2(5.9)$ & $41(9.1)$ & 0.75 \\
\hline & Sigmoid & $9(26.5)$ & $114(25.3)$ & 0.96 \\
\hline & Recto-sigmoidian & $8(23.5)$ & $81(17.9)$ & 0.55 \\
\hline & Rectal & 7 (20.6) & $176(39.1)$ & 0.04 \\
\hline & Syncronous & $1(2.9)$ & $18(4.0)$ & 0.89 \\
\hline
\end{tabular}

Table II. An opposite situation was encountered when the tumor was located in the sigmoid colon and the transverse colon, but the difference was not statistically significant.

As shown in Table III, rectal cancer was more common $(\mathrm{p}=0.05)$ in patients without cholelithiasis. We found the same modifications at the rectum and sigmoid colon as in patients that had a cholecystectomy.

\section{Discussions}

After analyzing the data from the three groups we found a statistically significant difference, mainly females in groups with biliary disease being affected compared to patients without cholelitiasis. Although the women:men ratio of 2:1 in groups with cholelitiasis and cholecystectomy can be explained by the increased incidence of biliary disease in women, their appearance after the $6^{\text {th }}$ decade of life (menopause) fits the data found in literature that suggests cholecystectomy as a risk factor for colon cancer in postmenopausal women [10].

The predominantly urban backgrounds in all groups, although not statistically significant, yields patients that have a Western-type diet, in which the increased levels of bile acids eliminated in the gastrointestinal tract act as precursors of colon carcinogenesis [11,12].

Regarding the location of neoplasia in the studied groups, we found that rectal cancer occurs frequently in individuals without gallstones; this number was significantly higher compared to patients who had cholecystectomy and to those who had cholelitiasis. Therefore, our results suggest that gallstones/cholecystectomy do not influence rectal cancer, this observation being confirmed by a number of authors. Tavani et al did not find an association between cholelitiasis and colorectal cancer [13]. Altieri et al suggest that cholelitiasis/cholecystectomy and colorectal cancer are not linked [14]. Goldach et al conclude that cholecystectomy does not cause cancer [15]. Chiong suggests that cholelithiasis increases the risk of rectal cancer, and cholecystectomy does not influence this pathology [16]. Schmidt et al obtained inconclusive results to draw a firm conclusion [17].

The location of tumors in different segments of the colon is proportionally different in each study group, but it has no statistical significance. This is probably the result of different pathways of tumor pathogenesis. It seems that for the proximal colon (up to the splenic angle) the main pathogenic mechanism is the instability of DNA microsatellite sequences (MSI) while in the distal colon carcinogenesis may be due to the chromosomal instability mechanism (CIM) $[18,19,20]$.

\section{Conclusions}

Similarly to other studies, our study suggests a slight increase in the overall incidence of colon cancer in women. Rectal cancer does not appear to be influenced by coexisting factors (lithiasis/cholecystectomy); further studies are needed to confirm or refute this statistical finding. We deem it necessary to conduct a prospective study over a longer period of time.

\section{References}

1. Bernstein $\mathrm{C}$, Holubec $\mathrm{H}$, Bhattacharyya AK, et al. Carcinogenicity of deoxycholate, a secondary bile acid. Arch Toxicol. 2011;85(8):863-71.

2. Goerg KJ, Nell G, Rummel W. Effect of deoxycholate on the perfused rat colon. Concentration dependence of the effect on net fluid and electrolyte transfer and the correlation with para cellular permeability. Digestion. 1983;26(3):105-13.

3. Gullikson GW, Cline WS, Lorenzsonn V, et al. Effects of anionic surfactants on hamster small intestinal membrane structure and function: relationship to surface activity. Gastroenterology. 1977; 73(3):501-511. 
4. Rafter JJ, Eng WW, Furrer R, Medline A, Bruce WR. Effects of calcium and $\mathrm{pH}$ on the mucosal damage produced by deoxycholic acid in the rat colon. Gut. 1986;27(11):1320-9.

5. Craven PA, Pfanstiel J, DeRubertis FR. Role of activation of protein kinase $\mathrm{C}$ in the stimulation of colonic epithelial proliferation and reactive oxygen formation by bile acids. J Clin Invest. 1987;79(2):532-41.

6. Milovic V, Teller IC, Faust D, Caspary WF, Stein J. Effects of deoxycholate on human colon cancer cells: apoptosis or proliferation. Eur J Clin Invest. 2002;32(1):29-34.

7. Kandell RL, Bernstein C. Bile salt/acid induction of DNA damage in bacterial and mammalian cells: implications for colon cancer. Nutr Cancer. 1991;16(3-4):227-238.

8. Bernstein H, Bernstein C, Payne CM, Dvorak K. Bile acids as endogenous etiologic agents in gastrointestinal cancer. World $J$ Gastroenterol. 2009;15(27):3329-40.

9. Roda E, Aldini R, Mazzella G, et al. Enterohepatic circulation of bile acids after cholecystectomy. Gut. 1978;19(7):640-9.

10. Hartz A, He T, Ross JJ. Risk factors for colon cancer in 150,912 postmenopausal women. Cancer Causes Control. 2012;23(10):1599605.

11. Chan AT, Giovannucci EL. Primary prevention of colorectal cancer. Gastroenterology. 2010;138(6):2029-2043.

12. Huxley RR, Ansary-Moghaddam A, Clifton P, et al. The impact of dietary and lifestyle risk factors on risk of colorectal cancer: a quantitative overview of the epidemiological evidence. Int J Cancer. 2009;125(1):171-80.
13. Tavani A, Rosato V, Di Palma F, et al. History of cholelithiasis and cancer risk in a network of case-control studies. Ann Oncol. 2012;23(8):2173-8.

14. Altieri A, Pelucchi C, Talamini R, et al. Cholecystectomy and the risk of colorectal cancer in Italy. Br J Cancer. 2004;90(9):1753-1755.

15. Goldacre MJ, Abisgold JD, Seagroatt V, Yeates D. Cancer after cholecystectomy: record-linkage cohort study. $\mathrm{Br} J$ Cancer. 2005;92(7):1307-1309.

16. Chiong C, Cox MR, Eslick GD. Gallstone disease is associated with rectal cancer: a meta-analysis. Scand J Gastroenterol. 2012;47(5):553-64.

17. Schmidt M, Småstuen MC, Søndenaa K. Increased cancer incidence in some gallstone diseases, and equivocal effect of cholecystectomy: a long-term analysis of cancer and mortality. Scand J Gastroenterol 2012;47(12):1467-74.

18. Fabian O, Oniu T, Bosu R, et al. Remarks regarding the relationship between biliary lithiasis and/or cholecystectomy and colorectal cancer. Jurnalul de Chirurgie (lasi). 2012; 8(3):245-254.

19. Gervaz P, Bucher P, Morel P. Two colons-two cancers: paradigm shift and clinical implications. J Surg Oncol 2004;88(4):261-6.

20. Azzoni C, Bottarelli L, Campanini N, et al. Distinct molecular patterns based on proximal and distal sporadic colorectal cancer: arguments for different mechanisms in the tumorigenesis. Int $\mathrm{J}$ Colorectal Dis. 2007;22(2):115-26. 